\title{
"Meus caros paes": A educação das Princesas Isabel e Leopoldina
}

"My dear parents": Education of Princesses Isabel and Leopoldina

Jaqueline Vieira de Aguiar Fundação de Apoio à Escola Técnica do Estado do Rio de Janeiro Maria Celi Chaves Vasconcelos Universidade Católica de Petrópolis Universidade do Estado do Rio de Janeiro

\section{Resumo}

No século XIX, as Princesas Isabel e Leopoldina tornaram-se as únicas herdeiras do Trono e da Coroa do Brasil. 0 trabalho objetiva analisar algumas das especificidades da educação das futuras soberanas por meio de uma pesquisa histórico-documental, tomando, como principais fontes, cartas, diários e estudos anteriores, relativos às duas Princesas. Inicialmente, abordam-se as dificuldades do Imperador para encontrar uma preceptora que se encarregasse da educação das Princesas, conforme as tradições da Corte portuguesa. Em seguida, volta-se para o cotidiano educativo na casa, ou seja, no Paço de São Cristóvão e no Palácio Imperial de Petrópolis. Finalmente, enfocam-se os mestres, as disciplinas e os horários de estudos das Princesas. Conclui-se que as Princesas foram educadas durante 14 anos em diversas disciplinas voltadas para as "ciências e letras", comumente proporcionadas aos homens, e com "prendas domésticas" destinadas às mulheres.

Palavras-chave: Princesa Isabel. Princesa Leopoldina. Brasil Império. Educação. Cartas.

\section{Abstract}

In the nineteenth century, the Princesses Elizabeth and Leopoldina became the only heir to the throne and the crown of Brazil. This dissertational study aimed to analyze the specific training of the future sovereign with regard to the educational curriculum taught to the players involved in it, the places where they had studied and the time dedicated to the formation of the Princesses heirs. The historical documentary research had as its main source of research the Princesses' letters. These letters were the main means of communication between the Princesses and their parents, for whom they wrote to inform them the quotidian of the "lessons". Initially, the study addressed the difficulties of the Emperor to find a tutor to take charge of Princesses education according to the traditions of the Portuguese Court. Then the investigation turned to the everyday education at home, that is, in the Palace of Saint Kitts and Imperial Palace in Petropolis. Finally, it came to the teachers, subjects and Princesses studying hours. It was concluded that the Princesses were taught for 14 years through several subjects aimed at the "arts and sciences", commonly given to men, and "occupation of a housewife" for women.

Keywords: Princess Isabel. Princess Leopoldina. Brazil Empire. Education. Letters. 
trabalho em pauta origina-se do constante contato com um cenário instigante e revelador: Petrópolis e o seu Palácio Imperial, construído em 1845, para ser a residência de veraneio dos monarcas, atraindo também importantes figuras políticas da Corte que acompanhavam o Imperador.

Nesse Palácio, durante boa parte do ano, nos meses de verão, residiam as Princesas Isabel e Leopoldina acompanhadas de suas amas, aias, açafatas e de sua preceptora a condessa de Barral que coordenava a educação das futuras soberanas, por meio de seus mestres e semanários, que subiam periodicamente a serra para ensinar as duas meninas.

Para ter acesso à documentação tão rara sobre a educação das Princesas, pertencente ao Arquivo Grão Pará, tornou-se necessário solicitar autorização aos descendentes da Família Imperial, pois o arquivo pertence à família, embora sob a custódia do Museu Imperial, sediado em Petrópolis. A autorização para consulta dos documentos foi dada pelo Príncipe D. Pedro Carlos de Orleans e Bragança e Bourbon, bisneto da Princesa Isabel, responsável pela guarda dos acervos, os quais contêm uma vasta documentação, rara e inédita sobre a Família Imperial. Esse é o caso das epístolas, que geralmente são de natureza íntima e particular, razão pela qual o acesso a elas não costuma ser fácil, pois o contato com as missivas predispõe certa invasão de privacidade, até para uma família tão ilustre e, por diversas vezes, pesquisada.

A pesquisa nas cartas escritas pelas Princesas revelou aspectos epistolares significativos, tomados como testemunhos escritos para a reconstrução da educação destinada à preparação das governantes'. As cartas apresentaram várias peculiaridades e códigos a serem decifrados. Para Mignot (2002, p. 11 15), elas "[...] constituem-se em documentos que permitem compreender itinerários pessoais e profissionais de formação, seguir a trama de afinidades eletivas e penetrar em intimidades alheias." Portanto, foi a partir da leitura das diversas missivas trocadas entre as Princesas, seus pais, seus mestres e seus familiares que se chegou à realização do estudo do qual deriva o texto apresentado a seguir.

Tendo em vista que a opção pelas fontes de investigação, voltou-se para a correspondência pessoal durante o período de formação educacional das Princesas brasileiras, as cartas foram "vasculhadas" no sentido de buscar-se, por meio delas, recompor o cotidiano de educação das herdeiras do Trono, assim como o contexto em que ocorria. $\bigcirc$ período escolhido para a seleção e 
análise foi de 1850 a 1864. Isto porque a educação formal das Princesas se inicia a partir do reconhecimento de Isabel como Princesa Imperial em 1850, o que perdurou até o casamento das duas, fato ocorrido no ano de 1864.

No contato com o acervo do Arquivo Grão Pará, foi constatado que as cartas da Princesa Leopoldina estão em menor número em relação aos da Princesa Isabel, pois Isabel possuía o hábito de mencionar as atividades educacionais realizadas também pela irmã, o que muito auxiliou a análise do processo de formação das duas herdeiras do Trono. Ainda consultando - Arquivo Grão Pará, foram encontradas cartas trocadas entre a Família Imperial e os seus parentes residentes na Europa. As cartas continham importantes elementos referentes à educação das duas Princesas, pois dão notícias aos familiares europeus tanto da formação como da progressão das meninas. Igualmente, percebeu-se que alguns mestres de Isabel e de Leopoldina costumavam se comunicar com as Princesas e com seus pais por meio de bilhetes e correspondências. As informações obtidas foram importantes por permitirem um maior entendimento sobre a relação estabelecida entre mestres, pais e alunas.

Na perspectiva proposta e dentro do recorte temporal estabelecido, foram selecionadas, portanto, as cartas tomadas como fontes principais da pesquisa, cujo critério era de que apresentassem indícios de como ocorreu a formação educacional das Princesas.

Não foram localizadas biografias da Princesa Leopoldina, mas alguns dos biógrafos da Princesa Isabel como Vieira (1 989), Queiroz (1966), Lacombe (1989) e Barmam (2005) fazem referência à filha caçula do Imperador no período da formação educacional das duas. Barmam (2005) menciona apenas que as duas Princesas iniciaram os estudos com o preceptor Francisco Crispiniano Valdetaro², em 1854³. Segundo Vieira (1989), a instrução da pequena Isabel começou alguns meses após o seu reconhecimento como Princesa herdeira, em 1850. E foi o próprio Imperador quem se responsabilizou pelas primeiras aulas, não só de lsabel, mas também de Leopoldina. Apenas mais tarde, chegaram os mestres supervisionados por D. Pedro II.

Os estudos das duas Princesas exigiam muita disciplina e os horários dedicados às atividades educacionais eram inflexíveis. (QUEIROZ). Lacombe (1 989, p. 22), ao enfatizar a preocupação de D. Pedro II em prepará-las para um dia assumirem o Trono do Brasil, afirma que "[...] foi ele o mais severo e o mais atento professor das Princesas." Quando o pai não se encontrava 
presente, era a dama Rosa de Santana Lopes, futura Baronesa de Santana, quem as acompanhava de perto, tarefa realizada desde o nascimento das mesmas. (VIEIRA, 1989).

Para compreender o contexto oitocentista em que ocorreu a educação das Princesas Isabel e Leopoldina, tomamos como referência o trabalho de Vasconcelos (2005), no qual se constata que a educação das elites do século XIX, assim como a dos príncipes e nobres, ocorria na "casa", ou seja, no espaço doméstico. Portanto, os mestres tinham um papel muito importante, especialmente os que exerciam a função de mestres e preceptores de príncipes, pois eram considerados praticantes de uma função nobre e, como tal, deveriam ser reconhecidos na sociedade por meio de privilégios. Segundo Bastos (apud VASCONCELOS, 2005, p. 62), entre os mestres destacavam-se os preceptores ou aios dos príncipes, que "[...] recebiam muitas graças e 'mercês especiais', tornando-se, por isso, dignos da maior consideração, que, naturalmente, acompanhava um emprego tão honroso." Afinal, o preceptor de um príncipe era responsável pela educação e instrução daquele que poderia um dia vir a governar o país. Assim sendo, ele

[...] acompanhava seu discípulo cerrando e abrindo as portas, despindo-o e vestindo-o, comendo com ele na mesma mesa, acompanhando-o nas jornadas ou passeios, assistindo, a seu lado, aos atos religiosos, estando junto com ele o tempo todo e em todos os lugares, nunca o perdia de vista, regulando todas as ações e os costumes de sua vida, tinha superintendência e voto na eleição de todos os Mestres que iriam participar de sua educação, estipulava todas as obrigações e deveres, bem como marcava as horas para as lições e estudos, atuava como se fosse pai, considerando-se que os verdadeiros estavam constantemente ocupados, preenchia todos os afazeres destes, sendo dito como 'segundo pai', o que The dava prerrogativas para preceder a todos os outros cargos da Casa Real. (VASCONCELOS, 2005, p. 66).

cargo de aio ou preceptor de príncipes era também de grande importância política. O aio se destacava porque não era apenas mais um mestre, mas também aquele que coordenava todo o trabalho dos demais mestres, tendo inclusive participação na decisão sobre sua escolha e permanência. Também eram diferenciados os ensinamentos dados a meninos e meninas, o que já demarcava o espaço reservado à mulher do século XIX. Enquanto aos 
meninos era requisitado o ensino das ciências e das letras, às meninas exigia-se apenas o conhecimento das "prendas domésticas", como costura, bordado dança e música. A justificativa para tal diferença, na época, relacionava-se ao fato de a principal finalidade para a educação de meninas ser o casamento e, consequentemente, a procriação. Aos meninos competia a condução econômica do país, fazendo-o prosperar e crescer.

A diferença na educação de homens e mulheres não ocorria apenas com as classes mais desfavorecidas, mas também com as elites e com a nobreza. Este modelo de educação masculina, na qual era priorizado o ensino das ciências e das letras, foi recebido pelo Imperador D. Pedro I e assim transmitido ao seu sucessor D. Pedro II. Porém, o destino fez de duas mulheres as herdeiras do Trono e da Coroa brasileira: Isabel, a Princesa Imperial, e sua irmã caçula, a Princesa Leopoldina, ambas filhas legítimas do segundo Imperador do Brasil. Mas, qual seria o tipo de educação dada a Isabel e a Leopoldina para que, no futuro, tivessem condições de governar o país? Embora Leopoldina não fosse a primeira na linha sucessória, por ser a filha mais nova, entendia-se que, na falta de sua irmã Isabel, ela também deveria estar apta a receber a missão de governar o Brasil, razão pela qual as duas 10 deveriam ser educadas da mesma forma.

As duas Princesas "[...] cresceram e educaram-se juntas, sob a orientação direta do pai austero, extremamente zeloso, tanto nesse, como em outros assuntos. Tiveram os mesmos mestres, os mesmos métodos de instrução [...]." (BRAGANÇA, 1959, p. 73). Quanto à formação conjunta das duas meninas, Argon (2006) argumenta que Isabel, durante a sua infância, enfrentou duas graves moléstias. Provavelmente, o Imperador temia perder Isabel, assim como ocorreu com os dois Príncipes varões, por isso, ofereceu as duas filhas a mesma educação rígida e refinada, condizente com as herdeiras da Coroa do Brasil, pois, na falta de lsabel, Leopoldina assumiria.

Embora as Princesas possuíssem mestres, o Imperador continuava a dedicar parte de seu tempo ao ensinamento das mesmas. Com o passar do tempo, ele sentiu necessidade de ter também uma encarregada da educação das Princesas e uma auxiliar. Preencheram esses cargos Luísa Margarida Portugal de Barros, a condessa de Barral ${ }^{4}$, no período de 1856 a 1864, como titular, e a Mademoiselle Victorine Templier ${ }^{5}$, de 1857 a 1864, como auxiliar da primeira. A condessa dedicava-se mais a Isabel e Templier a Leopoldina. (VIEIRA, 1989). Percebe-se que D. Pedro II não incumbiu a Imperatriz ${ }^{6}$, D. 
Teresa Cristina, dessa tarefa, por não achá-la capacitada para exercer a função. (BARMAN, 2005). Também as damas de companhia das Princesas não possuíam o grau de educação necessário para ensinar suas filhas, afirmara o próprio Imperador.

A condessa de Barral, escolhida para ser a encarregada da educação das Princesas, diferenciava-se dos outros mestres: ela coordenava os estudos das duas, mas também respeitava seus horários de lazer, passeando com as meninas ao lado de suas damas e também de sua auxiliar francesa a Mademoiselle Templier. (QUEIROZ, 1966). O Imperador sabia da importância de ter uma preceptora para coordenar os estudos das filhas, pois ele mesmo havia passado por essa experiência com Mariana Carlota de Verna Magalhães Coutinho, condessa de Belmonte? .

Em que pese também ser realizada na esfera doméstica, a educação das Princesas diferenciava-se da educação dada a meninas da elite no século XIX. As Princesas chegaram, inclusive, a compartilhar de alguns mestres do Imperador. Daibert Jr (2007), ao fazer uma comparação entre a educação recebida pela Princesa Isabel e por seu pai, nota que os dois receberam a mesma orientação educacional, a qual possuía características ilustradas, ou seja, voltadas para a valorização das ciências e das letras. No entanto, o autor ficou surpreso ao perceber que Isabel via os inventos tecnológicos do seu tempo como bençãos divinas ofertadas aos homens, enquanto o Imperador atrelava tais descobertas às ciências naturais.

Uma das inquietações de Daibert Jr (2007, p. 94-95), foi entender "[...] como a Princesa D. Isabel - filha de um Imperador considerado mecenas das ciências e das artes e herdeira de uma formação marcadamente ilustrada teria adquirido uma visão de mundo fortemente religiosa?" Ao tentar encontrar respostas, ele recorre a alguns documentos de estudos da Princesa, os quais, em sua visão, encontram-se impregnados de valores religiosos. Ele constata que Isabel esteve, durante toda a sua infância, rodeada por católicos fervorosos, incluindo alguns dos seus próprios mestres, como é o caso de Valdetaro e da condessa de Barral. O primeiro, inclusive, ensinava utilizando textos religiosos. A condessa, além de extremamente religiosa, exerceu uma grande influência na construção da personalidade da Princesa Isabel. (VIEIRA, 1989). Outra pessoa muito religiosa e fundamental na vida da Princesa foi sua mãe, D. Teresa Cristina, que nascera em Nápoles, um reino católico da região da Itália conhecido como "berço" do "ultramontanismo"8. 
Ao analisar algumas cartas trocadas entre mãe e filha, Daibert Jr (2007) constata a grande influência religiosa que Isabel recebeu por parte de sua mãe. Na sua concepção, de alguma forma, os católicos citados e/ou outras pessoas não mencionadas, podem realmente ter influenciado a construção da personalidade da Princesa Imperial. Segundo esse autor, na visão de mundo de Isabel, os preceitos cristãos se mostravam fundamentais para a ação dos governantes. Assim, ele pondera que Isabel, apesar de ter recebido uma educação de acordo com o "modelo oitocentista" prescrito aos príncipes, valorizando o humanismo, concebia a sociedade como um universo cristão. Dessa forma, ela expressava uma valorização aos governantes devotos da caridade, apropriando-se, assim, de preceitos tradicionais herdados do ideal dos reis medievais cristãos.

Segundo Calmon (1941), tanto a condessa quanto D. Pedro II não fizeram de Isabel uma "forte política". E o autor responsabiliza o Imperador por isso. Em sua análise, ele demonstra que o pai buscou preservar a filha do contato precoce com "assuntos de Estado", conforme ocorrera consigo próprio. E esta é também uma das principais críticas expressadas por Barman (2005, p. 751, para o qual D. Pedro II não foi capaz de fazer com que as herdeiras

12 do Trono tivessem a oportunidade de colocar em prática a instrução recebida. Em sua concepção, o aprendizado da Princesa Isabel teria sido mais eficaz se, desde cedo, ela começasse a realizar tarefas voltadas para a função que desempenharia no futuro como governante do Brasil. Assim, ela poderia relacionar o aprendizado na sala de aula com a prática. Na opinião do autor, o Imperador não adotou tal medida com a sua sucessora. Afinal, ele "[...] não discutia política com ela. Não a levava consigo em suas constantes viagens oficiais. Não a incluía nos despachos, nas reuniões semanais com o gabinete, tampouco the permitia participar das audiências públicas realizadas [...]." Ao invés disso, ele preferia manter não só Isabel, mas também Leopoldina, reclusas no palácio e longe da vida pública.

Para Barman (2005, p. 75) esse tratamento dispensado à Princesa herdeira ocorria porque D. Pedro II "[...] precisava ter o controle absoluto do seu mundo, tanto político como familiar." E "[...] ensinar D. Isabel a arte de governar significava criar, em casa e no governo, um centro de poder autônomo, portanto, capaz de competir com ele e até mesmo de substituí-lo". A percepção dessa ameaça "[... o o levou a excluir a herdeira dos negócios públicos." Tais questões também estão relacionadas a comportamentos, hábitos e 
costumes patriarcais do século XIX. É nesse contexto das relações sociais oitocentistas que se dá a formação educacional das duas Princesas.

\title{
Escrever para aprender, aprender para governar: a atuação dos mestres e preceptores na educação das Princesas
}

\begin{abstract}
Meus Caros Paes
O Bevilacqua veiu hontem ás 9 horas, e sahiu á 7 , e dice que tinhamos dado boa lição, e deixou-me uã - Air Suisse - para estudar toda pa amanhan. Hoje fui ao banho, de que muito gostei. Esta cartinha não pôde ir hoje, porque a barca partiu às 17 1 1 2, e nós esperámos pelo Valdetaro para corrigir os rascunhos e fazer-nos escrever. Adeus meus Caros Paes, recebam muitas saudades e deitem a sua benção à Sua filha affectuosa Isabel Christina. S. Christovão em 11 de abril de 1856. (ISABEL, 1856). 910
\end{abstract}

Nessa breve carta, a Princesa Isabel escreve do Paço de São Cristóvão aos pais, o Imperador do Brasil D. Pedro ll e a Imperatriz D. Teresa Cristina. Tudo indica que os soberanos encontravam-se em viagem, deixando as filhas sob os cuidados de Rosa de Sant'Anna e Domitilia Francisca, servidoras da Casa Imperial, que trabalhavam como damas em seus quartos. Verifica-se que, mesmo os pais estando distante do Paço, há uma preocupação por parte de Isabel, a Princesa Imperial, em mantê-los informados sobre o cotidiano educativo ao qual ela e sua irmã Leopoldina estavam submetidas. Isso fica claro quando afirma no plural, "O Bevilacqua veiu hontem [...] e dice que tinhamos dado boa lição [...]"1 1, e ainda, "[...] nós esperámos pelo Valdetaro para corrigir os rascunhos e fazer-nos escrever." ${ }^{2}$. (ISABEL, 1856).

De acordo com Isabel, o estudo do dia realizou-se com os mestres Bevilacqua e Valdetaro - ainda que não estivesse explícito nessa correspondência, o primeiro educador ensinava Música e o segundo era o responsável pelas disciplinas de Instrução Elementar e História Sagrada. ${ }^{13}$ Percebe-se o interesse da missivista em justificar aos pais o fato de a carta não ter seguido via barca naquele mesmo dia; afinal, ela ainda seria corrigida por Valdetaro. Talvez, o próprio mestre a orientasse a minutar a informação para que os soberanos tivessem a certeza de que o aprendizado havia ocorrido normalmente, apesar de 
eles não estarem presentes na casa, ou seja, no Paço de São Cristóvão, espaço onde naquela época do ano, ocorria a educação doméstica das duas Princesas.

A troca de cartas e bilhetes era o meio utilizado pelas Princesas Isabel e Leopoldina para se comunicar com os pais. A utilização desse recurso fazia-se necessária, pois a distância entre eles ocorria por vários motivos. Quando os Imperadores viajavam, também procuravam enviar correspondências às filhas para se informarem sobre o estado de saúde das meninas e também sobre as lições recebidas diariamente por elas. Tal fato fica bastante evidente nas cartas escritas por D. Pedro II às Princesas, no período em que os Imperadores visitaram as províncias do "Norte". A viagem ocorreu entre os meses de outubro de 1859 a janeiro de 1860, e as regiões visitadas foram: Espírito Santo, Bahia, Sergipe, Alagoas, Pernambuco e Paraíba ${ }^{14}$. Na carta do Imperador enviada a Isabel quando ele se encontrava em Recife, percebe-se sua preocupação com a educação da filha quando afirma: "Continue a dar boas lições." 15 (D. PEDRO II, 1859). Mesmo a distância, o Imperador fazia questão de se mostrar presente, incentivando as Princesas a estudar.

Até mesmo na residência oficial da família, no Paço de São Cristóvão, também chamada de Paço Boa Vista, a comunicação escrita se fazia presente, 14 pois as meninas não tinham autorização para andar pelos corredores, desacompanhadas e a qualquer hora do dia. (ARGON, 2006).

Ao mesmo tempo, as responsabilidades como Imperador do Brasil ocupavam grande parte do tempo de D. Pedro II, portanto, nem sempre as Princesas conseguiam falar com o pai quando desejavam. Ressalta-se ainda que a quantidade de disciplinas estudadas diariamente pelas Princesas era tão extensa que pouco tempo lhes restava para as demais atividades. No boletim de outubro de 1864, por exemplo, foram registrados os seguintes estudos:

Sagesse, Evangelho e Catecismo, Poesia Portuguesa, Escritura, Leitura Portuguesa e Francesa, Ortografia, Poesia Francesa, Literatura Portuguesa, Estilo em Português, Estilo em Francês, Cosmografia, Geografia, História do Brasil, História Moderna, História da França, História da Inglaterra, História do Consulado e Império, História Antiga, História Romana, História Santa, História da América, Retórica, Física, Economia Políica, Mineralogia e Geologia, Latim, Grego, Italiano, Alemão, Piano, Desenho e Tableau. ${ }^{16}$ (BOLETIM DA PRINCESA ISABEL, 1864). 
Apenas em alguns momentos, quando o Imperador se transformava em mestre das filhas, a comunicação se tornava mais fácil entre eles, mas, nesse caso, ele deixava de lado o papel de pai para se tornar um rigoroso mestre de meninas, conforme ver-se-á adiante.

No Brasil oitocentista, o Decreto das Escolas de Primeiras Letras (Decreto Imperial de 15 de outubro de 1827) relegou às mulheres que estudavam uma educação pautada nos ensinamentos das primeiras letras e das "prendas domésticas". Nesse sentido, a principal finalidade da educação feminina era o preparo para o casamento e a procriação.

No entanto, a morte dos dois filhos varões do Imperador D. Pedro II fez das Princesas Isabel e Leopoldina as únicas herdeiras do Trono e da Coroa do Brasil. Diante desse fato, as Princesas precisaram receber instrução digna de um soberano, posição normalmente ocupada por um homem, além dos ensinamentos destinados à mulher, como futuras mães e esposas.

$\bigcirc$ processo de formação educacional das Princesas iniciou-se em 1850 quando D. Pedro II principiou, ele próprio, a preparação das futuras soberanas, mas logo percebeu que não poderia encarregar-se ele mesmo desta tarefa e, segundo as tradições da Corte portuguesa, ao completar sete anos de idade o príncipe herdeiro deveria ter um aio ou preceptor dirigindo a sua educação. (BARMAN, 2005).

Ciente da importância da preceptora para a formação das Princesas herdeiras, D. Pedro II iniciou a "tarefa difícilima" de encontrar uma candidata à altura do cargo. Assim, convidou sua madrasta, D. Amélia Augusta Eugênia Napoleona de Beauharnais para desempenhar essa nobre missão. Na ocasião D. Amélia vivia em Lisboa. Ela havia se tornado a segunda Imperatriz do Brasil e rainha de Portugal ao se casar, aos 17 anos de idade, em 1829, com o viúvo D. Pedro I do Brasil, e IV de Portugal ${ }^{17}$. Mas, com a recusa da Imperatriz, D. Pedro II não viu alternativa a não ser incumbi-la de, ao menos, auxiliá-lo na busca por uma preceptora alemã, católica, viúva, sem filhos menores, maior de quarenta anos, dominando as línguas mais usadas, entendendo o português, possuindo gênio dócil, maneiras delicadas e conhecendo perfeitamente os diversos misteres em que as senhoras passavam suas horas vagas ${ }^{18}$. Para atender a essas recomendações, D. Amélia empenhou-se durante dois anos em encontrar na Europa, a senhora que preenchesse os requisitos necessários, e informava ao "filho" por meio de intensa correspondência o desenrolar 
de sua busca. No entanto, as exigências feitas por D. Pedro II eram muitas e, com o tempo, a Imperatriz D. Amélia sentiu a necessidade de pedir ao "filho" que encarregasse também a Princesa Francisca de Joinville, sua irmã, de fazer essa procura.

No momento, Francisca vivia na Inglaterra, estando casada com o Príncipe de Joinville, filho do Rei destronado Luís Felipe, da França. Assim, a Princesa Francisca enviou uma carta ao Imperador exaltando as qualidades da candidata ao cargo, sua antiga dama. Ainda, nessa correspondência, são colocadas pela irmã de D. Pedro II, as possíveis exigências para que a futura aia aceitasse o cargo.

Meu querido Mano Pedro

Vou começar esta carta falando-te logo do que nos interessa tanto da escolha da Aia. Creio que não podias escolher melhor do que a Barral a qual não é só mui bem educada como maneiras e princípios solidos em tudo. Mas tambem sabe bastante. Ella fala perfeitamente bem o francês, inglês e a sua língua. $O$ piano também é muito forte. Toca perfeitamente bem. E creio que com mestres debaixo da sua vista e direção tudo poderá ir como o desejas e teres para suas filhas uma educação excellente. [...] Eu espero que a Barral aceite. Tanto que outra vez se quizeres que trate negocios para ti, desejo que me falles com mais detalhes e que possa saber quaes são as proposições que fazes a pessoa pois com isso poderia arranjar os negocios melhor sabendo o que posso dizer e do que vou tratar [...]. Adeus meu Caro Pedro. Aceite um abraço bem do coração. Desta tua bem affectuosa Mana Francisca. ${ }^{19}$ (FRANCISCA, 1856).

Ao tomar conhecimento das suas aptidões, D. Pedro II não hesitou em entrar em contato com Luísa Margarida, a brasileira que se encontrava nas terras de seu pai, na Bahia. $\bigcirc$ mordomo Paulo Barbosa foi quem intermediou por meio de missivas a contratação da futura aia das Princesas, a viscondessa de Barral. Ao receber o convite, Luísa Margarida, uma mulher à frente de seu tempo, não respondeu de imediato, preferindo negociar um excelente ordenado, casa e carruagem Imperial a sua disposição, sendo prontamente atendida pelo Imperador do Brasil.

Com a morte de seu sogro, a preceptora chegou ao Rio de Janeiro, capital do Império, já na condição de condessa de Barral, dando início às 
suas funções como preceptora das Princesas em 9 de setembro de 1856 , quando foi registrado no diário da Princesa Isabel: "9 de 7 bro 1856 Veio hoje pela primeira vez minha aia a condessa de Barral e dei com Ella principio ao estudo da lingua Franceza, dei lição de piano; as três horas fomos passear á quinta, e de tarde estudei a lição de piano." 20

Partindo do princípio de que a educação de crianças nobres e principescas acontecia na casa, a pesquisa voltou-se para a residência oficial de Isabel e Leopoldina: o Paço de São Cristóvão. Em outro momento, as investigações deslocaram-se para o Palácio Imperial de Petrópolis, ambiente para o qual Isabel e Leopoldina se transferiam, principalmente no verão, sempre acompanhadas pela preceptora e pelos mestres. $\bigcirc$ objetivo principal da localização desses espaços, com base nas cartas das Princesas, foi demonstrar os recursos educacionais a elas oferecidos, tanto no que se refere ao espaço arquitetônico dos Palácios, como dos objetos neles contidos.

No Paço de São Cristóvão, Luísa Margarida recebeu o documento intitulado Atribuições Da Aia, por meio do qual foi informada de que só ela poderia intervir direta ou indiretamente na educação das meninas, lembrando ao Imperador e à Imperatriz tudo o que facilitasse o preenchimento deste dever do seu cargo. D. Pedro II também fez questão de deixá-la ciente da importância do seu cargo e do tipo de instrução que ele esperava que as Princesas herdeiras recebessem,

Quanto á educação só direi que o caracter de qualquer das princezas deve ser formado tal qual convem a Senhoras que poderão ter que dirigir o governo constitucional d'um Império como o do Brazil. A instrucção não deve differir da que se dá aos homens, combinada com a do outro sexo; mas de modo que não soffra a primeira. ${ }^{21}$ (ATRIBUIÇÕES DA AIA, [ 1857]).

Esse relevante documento, Atribuições Da Aia, encontra-se no Arquivo Histórico do Museu Imperial, antiga residência de verão das Princesas. Ele contém informações que auxiliam no entendimento das especificidades relacionadas ao cotidiano educativo vivido pelas Princesas herdeiras, nos Palácios Imperiais. Embora não esteja assinado, foi escrito por D. Pedro II e há neste mesmo arquivo, uma cópia com a caligrafia de D. Teresa Cristina, o que nos leva a pensar que a Imperatriz teve alguma participação na construção do texto juntamente com o soberano. Mesmo não estando datado, acredita-se que 
ele tenha sido formulado a partir de 1856, quando Luísa Margarida assumiu seu cargo como encarregada da educação das Princesas. A seguir, encontra-se um outro trecho do referido documento, no qual fica estabelecido que as Princesas Isabel e Leopoldina deveriam

Levantar ás 7 no inverno e 6 no verão. Até as 7 1/2, hora da missa, vestir, rezar e, no verão, enquanto não vão para a missa, ler cathecismo ou algum livro pio. 8 almoço; meio dia recordação do préparo das lições, leituras instructivas com a Aia e lições; descanso de meia hora conversando com a Aia, e continuação das lições até 2 horas; jantar; descanso como ao meio-dia até 3 rla; até 5 1 1 2, nos mezes de Dezembro, Janeiro e Fevereiro, _ 5, nos de Março, Abril, Agosto, Setembro, Outubro, Novembro, e 4 1/2 nos de Maio, Junho, e Julho - preparo das lições; passeio d' uma hora; descanso de meia hora; até as 8 preparo das lições, e leituras instructivas, ou conversa com a Aia, conforme chegar o tempo; ceia, e às 9 1/2 devem estar deitadas. Nos domingos e dias santos de guarda, desde às 9 até a hora da missa, que ouvimos juntos, cathecismo e leituras pias, e depois do descanso que se segue ao passeio, o qual poderá começar mais cedo, contanto que o sol não esteja ainda ardente, ou saião de carro devendo também então ir a Aia em sua companhia, recordação do preparo das lições e leituras instructivas ou conversa com a Aia, conforme chegar o tempo. Desde $1 / 2$ hora depois do jantar até o passeio brincarão e a Aia poderá não estar presente até chegar o tempo. Os [dias] de festa nacional serão empregados da mesma maneira, à exceção das leituras pias substituidas pelas outras. As leituras instructivas devem ter relação com as matérias ensinadas, sendo ora em portuguez, ora em qualquer das outras linguas. As visitas que (...) procurarem as princezas serão recebidas unicamente nos domingos; nas festas de guarda e nacionaes; nos dias dos seus annos; nos dos nossos; nos de seus nomes e nossos, e em qualquer outra ocasião que eu determinar, à excepção dos creados de honra e serviço. Só haverá férias em Petropolis, onde talvez seja alterada a distribuição do tempo. (ATRIBUIÇÕES DA AIA, [ 1857$]$ ]). ${ }^{22}$

Nota-se que o Imperador ao formular o regulamento exposto, pensou nas ocupações das meninas durante todos os dias do ano e até nos feriados santos e festivos, nos quais deveriam realizar leituras "pias" e/ou "instrutivas". Os horários de descanso e recreação proporcionados às Princesas, foram constantemente incentivados pela tia das meninas, a Princesa Francisca. Em uma misiva enviada por ela ao Imperador em 1858, encontam-se referências sobre o assunto como, 
"[...] toma bem sentido de não as cansar muito e que thes não falte recreação no meio do trabalho." ${ }^{23}$ (FRANCISCA, 1858).

Todas as atividades descritas no documento Atribuições Da Aia, deveriam ser realizadas pelas Princesas sob a orientação da condessa de Barral, pois o sucesso do roteiro educativo dependia de sua atuação como preceptora. Ela precisava cuidar para que todas as tarefas estabelecidas fossem realmente desempenhadas pelas Princesas. No ano seguinte a sua chegada, a preceptora recebeu uma ajudante, a Institutrice francesa Victorine Templier, isto porque uma auxiliar era necessária devido às atribuições de Luísa Margarida no cotidiano educativo das Princesas e o programa estabelecido pelo Imperador. A auxiliar da condessa de Barral foi indicada pela Rainha Maria Amélia Teresa de Bourbon ${ }^{24}$, conforme carta dela própria abaixo transcrita.

Claremont, 7 de fevereiro de 1857.

Meu caro sobrinho, Devo the dizer que segundo o desejo que você me exprimiu em sua carta de 15 de dezembro de 1856, Madame Templier aceita o posto que você a propõe e tendo alguns arranjos de família a terminar antes de se expatriar por muitos anos, ela só partirá pelo navio em 9 de maio, para se colocar à disposição da Condessa de Barral para a ajudá-la a preencher a importante tarefa de educar suas caras filhas. A partir do que você me escreveu eu a assegurei que você teve a bondade de pagar sua viagem [...]. De sua dedicada santa e amada Maria Amélia. ${ }^{25}$ (AMÉLIA, 1857).

Luísa Margarida, auxiliada por Victorine Templier, acompanhava as Princesas durante todo o dia, auxiliando-as nas tarefas, dando lições, levando-as aos lugares que fossem necessários, influenciando no comportamento das duas e orientando seus mestres e damas. Longe de ser apenas uma dama, como fora para Francisca, Luísa Margarida não apenas formava duas esposas de príncipes estrangeiros, mas principalmente, duas mulheres que deveriam ser educadas para governar.

\section{O cotidiano das lições nos Paços onde as Princesas eram educadas}

Isabel e Leopoldina viveram grande parte da infância no Paço de São Cristóvão. A propriedade foi presente do comerciante Elias Antonio Lopes ${ }^{26}$ ao 
bisavô das duas, o Príncipe Regente D. João VI, que chegou ao Brasil com sua Corte em 1808. (BARMAN, 2005). O Paço abrigou a Família Real enquanto esteve no Brasil, passando, posteriormente, a ser a residência oficial da Família Imperial, conforme o desejo de D. Pedro I, mantido por D. Pedro II.

Quando as Princesas saíam de São Cristóvão era para passar as férias em outros locais, como é o caso do Palácio Imperial de Petrópolis, para onde se dirigiam acompanhadas pela preceptora e pelos mestres. Segundo Barman (2005), a propriedade serrana havia sido comprada por D. Pedro I e, quando este abdicou, as terras caíram nas mãos dos credores, sendo finalmente resgatadas em 1840 em função da maioridade de D. Pedro II. Anos depois, transformaram-se em residência de veraneiro da Família Imperial e, consequentemente, no palco do aprendizado de Isabel e Leopoldina.

De acordo com Aguiar (2012)27, os espaços privados, semipúblicos e públicos, tanto do Paço de São Cristóvão como do Palácio Imperial de Petrópolis, são reconhecidos como palco do aprendizado das Princesas herdeiras, revelando-se (segundo as cartas das meninas, os cadernos, o diário da Princesa Isabel e também do Imperador) como verdadeiros "espaços do conhecimento", por instigar e proporcionar a produção intelectual. Entre os 20 espaços analisados pela autora pertencentes aos dois Paços destacam-se o Salão de Jantar, a Biblioteca, o Gabinete de Estudos, o Gabinete de Química, - Observatório Astronômico, o Museu do Imperador, a Sala de Teatro, a Sala de Visitas e do Piano da Imperatriz, a Sala de Música e Baile, a Sala de Costura e a Sala de Arte Sacra foram os ambientes, atualmente reconstruídos como museus, onde as meninas instruíram-se com disciplinas voltadas para o conhecimento das "ciências e letras" e das "prendas domésticas", sobressaindo as figuras do Imperador e da Imperatriz, respectivamente.

As "prendas domésticas" constiuíam-se em trabalhos manuais realizados no lar pelas moças, mães e esposas, sendo valorizada a mulher oitocentista que dominasse esse saber. A mestra responsável pelo ensino de bordados e costura foi Madame Diémer ${ }^{28}$. Não se tem conhecimento se, no Paço de São Cristóvão, havia uma sala específica para essas lições, todavia, nas cartas de Isabel, encontram-se comentários sobre alguns trabalhos manuais confeccionados por ela em sua casa.

SC. 4 de Outubro de 1859. Minha querida Mamãe. [...] 
Hontem eu comecei o trabalho para o Monsenhor Narciso. É um véo para o calyse. A marqueza e o maquez de'ltanhaem esteve hoje aqui e viu-nos dansar a varsovianna e a Polka [...]. Eu hontem já dei as minhas lições. No sábado eu ehei de ver se arranjo um mappa das notas da semana para the mandar e tambem do Papae. Tomára não mandar mais mappas porque He sinal que Meus Caros Paes já estão de volta. Hoje a noite alinhavei uã touca, Cortei um roupão, alinhaveit-o um pouco, como não estava bem cortado, Cortei um outro, mas não tive tempo de alinhaval-o. Tenho medo de que mamãe se zangue d'isto porque eu the prometti que não cozia de noite. Mas hontem foi com pontos não pequenos e hoje alinhavei. Perdoe-me a letra e a ortographia. (ISABEL, 1859). ${ }^{29}$

SC. 11 de Outubro de 1859. Minha querida Mamãe. [...] Hoje alinhavei uã coisinha e chuliei um vestidinho d'uma bonequinha. (ISABEL, 1859). ${ }^{30}$

SC. 17 de Outubro de 1859. Minha querida Mamãe. [...]. Hoje bordei com a Madame Diémert. (ISABEL, 1859). ${ }^{31}$

As cartas confirmam o gosto de Isabel pelas "prendas domésticas". Em suas costuras, a Princesa mostra-se perfeccionita e exigente consigo mesma, decidindo cortar novamente uma peça que, em sua concepção, "não estava bem cortada". É provável que a Princesa encarasse o aprendizado como parte de suas brincadeiras, já que fazia roupinhas para suas bonecas. Mesmo à noite e desprovida de iluminação adequada, ela habitou-se a costurar, talvez por desejar muito, e/ou simplesmente para não atrapalhar o aprendizado das demais disciplinas realizadas durante o dia. Em vários trechos das epístolas analisadas, ela pede perdão à mãe por "coser" à noite. Muitas vezes, a costura não era, sequer, para si própria, e sim uma doação de caridade.

Conforme mencionado anteriormente, o ensino das "ciências e letras" tinha como referência D. Pedro II. Entre os espaços do conhecimento existentes no Paço de São Cristóvão, está a "Biblioteca Particular de Sua Majestade Imperial", que se localiza no terceiro pavimento. De acordo com Dantas (2007), a biblioteca de D. Pedro II teve origem nas obras trazidas para o Brasil por D. João VI e foi, posteriormente, ampliada por sua mãe, D. Leopoldina, e ainda mais por ele próprio e D. Teresa Cristina. ${ }^{32}$ 
Imperador era consciente da importância dos livros para a plena formação de um soberano. Afinal, ele próprio, desde a infância, debruçava-se sobre vários volumes até altas horas da noite. Com suas filhas não seria diferente: ele não só encomendava os livros que normalmente vinham da Europa, mas também as incentivava à leitura, conforme se pode verificar na missiva enviada pelo monarca a Isabel em 14 de março de 1862.

Cara Izabel [...] Mando-te o 'Petit Anarcharsis' que podes ler quando quizeres; mas é preciso querer e não posso deixar de lembrar-the de que só tem 20 e tantas paginas de livro portuguez que te dei enquanto o livreiro mandou buscar a França o 'Petit Anarcharsis' e este de lá veio. Adeus! Descansa-te bem hoje; porem se lá estiver - Paula Candido não te esqueças da Physica. Seu Pae extremoso Pedro. (D. PEDRO II, 1862).33

No fragmento, D. Pedro II explica a Isabel que não bastava que ele comprasse e indicasse a leitura. Era necessário que ela lesse os livros encomendados e trazidos da França. Sobre a obra, Daibert Jr fez as seguintes considerações:

O livro encomendado era uma edição resumida de 'Le Voyage du jeune Anacharsis en Grèce dans le milieu du quatrième siècle avant l'ère vulgair'. A obra havia sido publicada, originalmente, em sete volumes, no ano de 1788, por Jean-Jacques Barthélémy 11716 1795), e várias vezes reeditada ao longo do século XIX. Trata-se de um grande clássico, elaborado pelo autor durante trinta anos após uma visita a Pompéia em 1755. O livro traz uma meticulosa descrição da civilização grega e apresenta uma discussão sobre artes, religião, ciências e filosofia da Grécia Antiga, sobretudo sob o governo de Felipe da Macedônia. Anarcharsis era um jovem herói fictício que, em visita às ilhas, travava discussões a respeito das instituições gregas com os grandes filósofos da antigüidade. É neste sentido que o livro de Barthélémy é considerado uma das grandes contribuições no processo de popularização de uma literatura que consagrava a viagem como forma de conhecimento. (DAIBERT JR, 2007, p. 103-104, grifos do autor).

No dia seguinte ao envio do livro, D. Pedro II já cobrava: "Cara Izabel [...] Que tens lido do 'Petit Anarcharsis'?" (D. PEDRO II, 1862). ${ }^{34}$ Ao escolher essa obra, D. Pedro II esforça-se para incutir nas Princesas herdeiras o gosto pela arte, ciência, filosofia, mas também pela política e cultura, visto que 
a obra destaca a figura de um soberano que, apesar de imperialista, como era o caso de Alexandre da Macedônia, também buscava preservar a cultura dos mais variados povos que dominava.

Como se pode avaliar, Isabel e Leopoldina estudavam intensamente e essa era a rotina diária das Princesas. Na carta, o pai até tenta permitir a Isabel algum descanso, mas, ao mesmo tempo, lembra que se Paula Cândido, mestre de física e química, por lá estivesse, que ela, então, aproveitasse seus ensinamentos. Com tais atitudes, D. Pedro II deixava subentendido que a prioridade da Princesa era preparar-se adequadamente para um dia ocupar o lugar que no momento era dele, mas que no futuro, ela tomaria. $\bigcirc$ mesmo valia para Leopoldina na falta da irmã.

Constata-se que, no fragmento citado, não há apenas um pai escrevendo à filha para cobrar-the a atenção aos estudos e a leitura de determinados livros, mas principalmente se reconhece o rigoroso mestre de suas herdeiras. Em seu diário, o Imperador confessou, "[...] sou dotado de algum talento; mas o que sei devo-o sobretudo à minha aplicação, sendo o estudo, a leitura e a educação de minhas filhas, que amo extremosamente, meus principais divertimentos." (PEDRO II, 1861)35. Logo se percebe que D. Pedro II, além de zeloso em seus estudos, também dedicava-se intensamente à formação educacional das filhas, não escondendo sua afeição pelo ofício de educador.

A partir dos indícios de que o Imperador já exercia a função de mestre junto às filhas, pode-se cogitar que ele tenha preparado aulas para as duas em seu gabinete de estudos, identificado neste artigo como um dos espaços do conhecimento existente na casa do soberano. Em três missivas enviadas por D. Pedro II às filhas, no período de 1859 a 1861, são encontrados alguns vestígios de como ele conduzia a educação de lsabel e Leopoldina.

Recife 18 de 1 bro de 18591 da madrugada. Cara lzabel [...] Mande me dizer o que indica que uma equação é do $2^{\circ}$ grau, e qual a formula de resolvel-a. Fale-me também dos logaritimos dizendo-me o que são e para que servem. Quando responderes não entraves senão contigo mesma, tendo-me escrito o Candido Baptista que já The explicou estas matérias [...]. (PEDRO II, 1859). ${ }^{36}$

Rio 24 de março de 18616 horas da manhaã. Caras Filhas (...) Não s' esqueção da minha figura geometrica e passem esta semana tão santinhas como Ella [...]. (PEDRO II, 1861).37 
Rio 28 de março de 1861 Minhas Caras Filhas [...] Ahi vae um abraço por boas festas e domingo terão as caixinhas de amêndoas que eu mesmo escolherei para serem bonitas. Não me conterão só com a figura geometrica; quero também uma semana, pelo menos, de lições muito bem dadas [...]. (PEDRO II, 1861).38

A Física, a Matemática, o Latim e a Literatura faziam parte do conjunto de disciplinas ministradas pelo Imperador às filhas, o que é possível verificar em seu diário, quando registra os detalhes do cotidiano educativo das Princesas.

Assisto às lições do Sapucaíi9 de inglês e de alemão dadas a

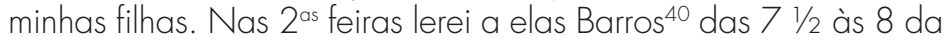
noite; 3as Lusíadas, das 10 1/2 às 11 da manhã; das 3 às 4 dar- thes-ei lição de matemáticas, e latim com elas das 7 às 8 da noite; 4as, latim com minhas filhas das $10 \frac{1}{2}$ às $11 ; 5$ as, Lusíadas das 10 $1 / 2$ às 11 ; explicarei a minhas filhas a física de Gannot das 3 às 4 , e latim com elas das $71 / 2$ às 8 da noite e nas 6 as latim com minhas filhas das $10 \frac{1}{2}$ às 11 , e Barros das 7 às 8 da noite. (PEDRO II, 1862). ${ }^{41}$

24 mestre das Princesas, além de assistir às aulas das filhas, também procurava estabelecer os horários em que ele mesmo as educaria. Entre as leituras escoIhidas pelo monarca para ler com as meninas, estão duas obras clássicas da Literatura Portuguesa, de autoria de João de Barros e Luís Vaz de Camões. Os Lusíadas, obra do segundo autor, destaca-se por ser considerada uma verdadeira epopeia portuguesa.

Num documento pertencente ao Arquivo Histórico do Museu Imperial e denominado como Papeis relativos à educação das Princesas ${ }^{42}$, são apresentados os horários e as disciplinas que deveriam ser estudadas diariamente pelas Princesas no ano de 1862. $O$ manuscrito encontra-se em língua francesa e com a caligrafia da Institutrice $M^{\text {lle }}$ Templier. A partir dos apontamentos contidos nesse documento reconhecido por Aguiar (2012) como um "manual educativo", foi elaborado o Quadro a seguir. 
Quadro - Dias e horários das disciplinas estudadas pelas Princesas no ano de 1862

\begin{tabular}{|c|c|c|c|}
\hline Horário & Dias da Semana & Horário & Dias da Semana \\
\hline & Segunda-feira & & Quinta-feira \\
\hline $7-71 / 2$ & Estudo da História de Portugal & $7-71 / 2$ & Geografia \\
\hline $71 / 2$ a 9 & $\begin{array}{l}\text { Caminhada, Almoço, Visita da } \\
\text { mãe da mmmmlmpelmperatriz }\end{array}$ & $9-10$ & $\begin{array}{c}\text { Dever de estilo Alemão e } \\
\text { Francês }\end{array}$ \\
\hline $9-10$ & Estudo do Piano & 10-11 & Aula de Inglês \\
\hline $10-11$ & Dever de Latim - Ditado francês & $\begin{array}{c}11-11 \\
1 / 2 \\
\end{array}$ & Camões \\
\hline 11 & $\begin{array}{c}\text { Gramática Francesa - } \\
\text { Homônimos }\end{array}$ & $\begin{array}{c}11 \frac{1 / 2}{} a \\
14\end{array}$ & $\begin{array}{l}\text { Hist. de Portugal e Inglat. - } \\
\text { Geografia Inglaterra. }\end{array}$ \\
\hline $12-14$ & Desenho & $15-16$ & $\begin{array}{l}\text { Escrita da História da } \\
\text { Inglaterra }\end{array}$ \\
\hline $14-15$ & Jantar & $16-17$ & O Sr. Candido Baptista \\
\hline $15-16$ & Aula de Alemão & $\begin{array}{c}19-19 \\
1 / 2\end{array}$ & Latim com Imperador \\
\hline $16-17$ & Aula de Latim com o Visconde & $\begin{array}{c}191 / 2- \\
20 \\
\end{array}$ & Jantar - Oração \\
\hline $17-18$ & Andar - Recreação & $20-21 \frac{1}{2}$ & $\begin{array}{c}\text { Gramática - Versos } \\
\text { portugueses }\end{array}$ \\
\hline $\begin{array}{c}19-19 \\
1 / 2\end{array}$ & Leitura de Barros & & \\
\hline $\begin{array}{l}191 / 2- \\
208:\end{array}$ & Ceia - Oração & & \\
\hline \multirow[t]{2}{*}{$20-21 \frac{1}{2}$} & $\begin{array}{c}\text { História da França - Dever de } \\
\text { Inglês }\end{array}$ & & \\
\hline & Terça-feira & & Sexta-feira \\
\hline $7-71 / 2$ & Estudo de verso Francês & $7-71 / 2$ & $\begin{array}{c}\text { Estudo da História de } \\
\text { Portugal }\end{array}$ \\
\hline $71 / 2$ a 9 & Almoço & $9-10$ & Estilo Português - Aritmética \\
\hline $9-10$ & Dever de Alemão e de Latim. & 10-11 & Cópia da Cosmografia \\
\hline $10-11$ & Aula de Inglês & $11-14$ & $\begin{array}{c}\text { Piano - Inglês - Latim com o } \\
\text { Imperador }\end{array}$ \\
\hline $\begin{array}{l}11-11 \\
1 / 21 / 2:\end{array}$ & Camões & $15-16$ & Alemão \\
\hline
\end{tabular}




\begin{tabular}{|c|c|c|c|}
\hline $\begin{array}{c}11 \frac{1}{1 / 2} \\
-14 \\
21 \mathrm{pm}:\end{array}$ & $\begin{array}{c}\text { Piano - Hist. de Portugal e da } \\
\text { França }\end{array}$ & $16-17$ & $\begin{array}{l}\text { Literat. Portuguesa com o } \\
\text { Visconde }\end{array}$ \\
\hline $14-15$ & Jantar & $19-21$ & Barros Princesas. \\
\hline $15-16$ & Lição de Física & $21-22$ & $\begin{array}{c}\text { Tableau da ldade - Média } \\
\text { - Francês } \\
\end{array}$ \\
\hline 16-17 & Botânica aprendida e recitada & & \\
\hline $17-19$ & Recreação & & \\
\hline $\begin{array}{c}19-19 \\
1 / 2 \\
\end{array}$ & Latim com Imperador & & \\
\hline $\begin{array}{c}191 / 2 \\
-20\end{array}$ & Ceia - Oração & & \\
\hline $20-21$ & $\begin{array}{c}\text { Tableau da Idade - Média- } \\
\text { Francês }\end{array}$ & & \\
\hline & Quarta-feira & & Sábado \\
\hline $7-71 / 2$ & Estudo da História da Inglaterra & 7-9 & $\begin{array}{l}\text { Missa na Glória - } \\
\text { Evangelho no carro }\end{array}$ \\
\hline $71 / 2$ a 9 & Almoço & $9-10$ & $\begin{array}{c}\text { Alemão - Latim com o } \\
\text { Imperador }\end{array}$ \\
\hline $9-10$ & Estudo do Piano & $10-11$ & Inglês \\
\hline $10-11$ & Estilo em Português - Inglês & $11-14$ & Camões - Exames \\
\hline 11 & $\begin{array}{l}11 \text { horas: Mitologia - Hist. } \\
\text { Sagrada }\end{array}$ & $15-16$ & Física \\
\hline $12-14$ & Desenho & $16-17$ & Piano \\
\hline $15-16$ & Alemão & $\begin{array}{c}19-19 \\
1 / 2 \\
\end{array}$ & Latim com o Imperador \\
\hline $16-17$ & Literatura Portug. com o Visconde & $20-21 \frac{1}{2}$ & $\begin{array}{c}\text { Desenho - Leitura religiosa/ } \\
\text { divertida }\end{array}$ \\
\hline $\begin{array}{c}19-19 \\
1 / 2 \\
\end{array}$ & Barros & & \\
\hline $\begin{array}{l}191 / 2 \\
-20 \\
\end{array}$ & Ceia-Oração & & \\
\hline $20-21$ & História de Portugal - Problemas & & \\
\hline
\end{tabular}

Fonte | Aguiar $(2012)^{43}$ 
Ao analisar o Quadro anterior, percebe-se que os Imperadores também tinham hora marcada para estar com suas filhas. D. Pedro II ministrava-thes lições e D. Teresa Cristina para visitá-las, o que ocorria geralmente no período do almoço, talvez para não atrapalhar as lições. As atividades educacionais das meninas realizavam-se de segunda a sábado por volta das 7 horas da manhã, podendo se estender até as 22 horas, o que perfaz um total de 15 horas diárias. Porém, ao descontar as 4 horas em que paralisavam a instrução para a realização das refeições, da oração e da recreação, chega-se à média de 11 horas diárias dedicadas às lições, no que se conclui ser uma carga horária extremamente rigorosa para as duas meninas cumprirem e aprenderem as mais variadas disciplinas.

No Quadro apresentado, é possível identificar ainda alguns mestres das Princesas brasileiras, Isabel e Leopoldina. Ao consultar a bibliografia selecionada ${ }^{44}$, as cartas das Princesas (1854-1862), os Livros de Pagamentos dos Servidores da Casa Imperial, do Livro de Assentamento dos Mestres de Sua Majestade o Imperador e Sereníssimas Senhoras Princezas e das Folhas dos Vencimentos dos Mestres da Imperial Família (1 850-1864), chegou-se ao número de 25 professores, sendo 22 homens e três mulheres. Destas, duas eram a preceptora, a auxiliar e ainda Madame Diémer. Entre os 25 professores, cinco já haviam atuado como mestres de D. Pedro II e de suas irmãs, anos atrás. A prática educativa de alguns desses mestres foi pesquisada nas cartas das Princesas, cuja correspondência revela que davam lições nos Paços em dias determinados pelo Imperador, estando subordinados à preceptora, que constantemente os avaliava e informava a D. Pedro II os métodos e procedimentos adotados.

Nas cartas de Isabel e Leopoldina, percebe-se que elas eram constantemente avaliadas pelos mestres, pela preceptora e até por seus médicos. As Princesas enviavam aos pais, por meio de cartas, as notas obtidas, e igualmente a preceptora comunicava aos Imperadores as notas e o comportamento moral de suas discípulas.

A formação educacional das Princesas brasileiras Isabel e Leopoldina ocorreu ao longo de 14 anos dedicados à intensa rotina de estudos. Em 1858, ainda no meio do processo, ambas deram a entender, em duas epístolas (abaixo transcritas), que estavam cientes da proporção do projeto educativo a que estavam submetidas e demonstraram gratidão ao pai, comprometendo-se a provar, por meio da "aplicação", o investimento educacional que thes era feito. 
São Cristóvão 2 de dezembro de 1858. Meu Caro Papai, Eu aproveito o dia do seu nascimento para exprimir todos os meus votos para a sua felicidade. Eu peço a Deus que conserve para mim por longo tempo um pai tão bom, que cuida tanto de minha educação, e eu espero através de minha aplicação poder um dia The provar meu reconhecimento. [...] Sua respeitosa e afetuosa filha, Leopoldina Teresa. (LEOPOLDINA, 1858). ${ }^{45}$

São Cristóvão 2 de dezembro de 1858. Meu Caro Papai, Parece-me que esta carta deveria ter sido escrita em Português uma vez que é a língua de nosso país que exprime ainda melhor o que meu coração sente por você de reconhecimento e ternura, mas eu a escrevo em Francês, para que julgue os pequenos progressos que eu devo ao seu terno cuidado com minha educação. Tenha a certeza, meu caro papai, que eu farei todos os meus esforços para The provar meu profundo reconhecimento. [...] Sua respeitosa e afetuosa filha, Isabel Cristina. (ISABEL, 1858). ${ }^{46}$

A educação das Princesas Isabel e Leopoldina só findou por ocasião de seus respectivos casamentos. Em 15 de outubro de 1864, casou Isabel com - Príncipe francês Luís Felipe Maria Fernando Gastão de Orléans, Conde d'Eu

28 e, em 15 de dezembro, foi a vez de Leopoldina casar-se com Luís Augusto Maria Eudes, Duque de Saxe-Coburgo-Gotha, vindo da Áustria.

\section{À guisa de conclusão...}

D. Pedro II seguiu firme no seu compromisso de formar duas futuras governantes, contratando mestres das mais complexas disciplinas e conduzindo todo o processo educativo finalizado em 1864. Um ano antes do término, o Imperador escreveu à Princesa Francisca para tratar do casamento das filhas. Nessa carta"7, ele confirmou ter proporcionado as duas filhas os "conhecimentos mais proprios do outro sexo" para que elas tivessem condição de assumir o Trono e a Coroa do Brasil quando chegasse o momento.

Embora as Princesas tenham recebido a mesma educação, ao se comparar as cartas das duas irmãs, verifica-se que Isabel era a mais comprometida em informar "o desenrolar" de sua formação educacional. Também era a mais cobrada pelo Imperador, a mais dedicada nas lições e, consequentemente, a mais bem preparada para governar. E Isabel estava ciente de sua 
condição como mulher e de suas responsabilidades para com o seu país, enfrentando junto à irmã uma árdua rotina de estudos. Ainda que distantes, os pais acompanhavam todo o processo por meio das epístolas das duas meninas e respondiam com incentivos para darem "boas lições" e a se transformarem em duas futuras soberanas.

\section{Notas}

1 As duas Princesas receberam a mesma educação para a suposta herança do Trono do Brasil, tendo em vista que na falta de uma, a outra assumiria o Trono, como se verá adiante.

2 Nascido em 1805, no Rio de Janeiro, onde faleceu em 10.01.1862, sepultado no cemitério de São João Batista. Francisco Crispiniano Valdetaro foi o mestre de Instrução Elementar das Princesas, dando continuidade a alfabetização iniciada pelo pai Imperador. Segundo Daibert Jr (2007, p. 96), Valdetaro "[...] atuava como pedagogo e dirigia os estudos gerais de D. Isabel e de sua irmã, D. Leopoldina, desde 1854." Contudo, de acordo com o estudo de Aguiar 12012 , p. 205), se de fato, o mestre em questão dirigiu a educação das Princesas, ele o fez apenas entre os anos de 1854 a 1856, antes da preceptora condessa de Barral assumir este cargo. Até porque, nas cartas de Isabel e Leopodina, Valdetaro é apontado como mais um, entre tantos outros mestres que as atendiam em casa, no espaço doméstico de seu lar, estivessem elas no Paço de São Cristóvão ou no de Petrópolis.

3 Outros autores como Queiroz (1966), Vieira (1 989), Lacombe (1989), Argon (2006) e Barmam (2005) mencionam apenas que as duas Princesas iniciaram os estudos com o preceptor Francisco Crispiniano Valdetaro, em 1854.

4 Luísa Margarida Portugal de Barros, a condessa de Barral, foi encarregada da educação das Princesas no período de 1856 a 1864.

5 Victorine Templier era uma dama francesa que foi auxiliar da encarregada da educação das Princesas, a Barral, no período de 1857 a 1864.

6 A Imperatriz D. Teresa Cristina, nasceu em Nápoles, um reino católico da região da ltália conhecido como berço do "ultramontanismo". A, então, Princesa, chegou ao Brasil em 1843 para ser a esposa do Imperador D. Pedro II.

7 Mariana Carlota de Verna Magalhães Coutinho, primeira e única condessa de Belmonte, foi camareira-mor na época do Primeiro Império e a responsável pelos estudos iniciais de D. Pedro II; era considerada como uma segunda mãe pelos filhos de D. Pedro I. $\bigcirc$ título de condessa de Belmonte foi criado por D. Pedro II por decreto de 5 de maio de 1844.

8 Doutrina e política católica que tem em Roma a sua principal referência. $\bigcirc$ ultramontanismo surgiu na França na primeira metade do século XIX. Sua ideologia reforça e defende o poder e as prerrogativas do papa em matéria de disciplina e fé. http://dicionario.sensagent.com/ultramontanismo/pt-pt. Sobre o assunto ver Daibert Jr (2007).

9 Carta da Princesa Isabel dirigida a D. Pedro II e a Teresa Cristina. São Cristóvão, 11 de abril de 1856. (AGP- XLL-3). 
10 Optou-se por manter a grafia original das cartas para melhor visualização do leitor.

11 Trecho da carta da Princesa Isabel dirigida a D. Pedro II e a Teresa Cristina. São Cristóvão, 11 de abril de 1856 (AGP-XLI-3).

12 Idem

13 Cf. Livro de Assentamento dos Mestres de Sua Majestade o Imperador e Sereníssimas Senhoras Princezas - 1833-64- Mordomia da Casa Imperial - Códice 01 - Volume 81 - Arquivo Nacional; e Diário da Princesa Isabel (AGP).

14 Cf. palavras proferidas por D. Pedro II no Encerramento da Assembleia Geral ocorrida em 11 de setembro de 1859. Fallas do Throno desde o ano de 1823 até o ano de 1889.

15 Carta de D. Pedro II a Princesa Isabel. Recife, 28 de novembro de 1859. (AGP- XXXIX-1).

16 Boletim da Princesa Isabel de outubro de 1864 Alguns termos são próprios da época como Sagesse, identificado como sabedoria, e Tableau, que pode significar tanto pintura como quadro. $O$ original encontra-se em francês. (AGP).

17 Sobre o assunto ver Bragança. "A princesa flor"- Dona Maria Amélia, a filha mais linda de D. Pedro I do Brasil e IV do Nome de Portugal. Edição direção regional assuntos culturais, Funchal, Madeira, 2009.

18 Cf Carta (Rascunho) de D. Pedro II à Imperatriz D. Amélia. [Rio de Janeiro, 1853]. Museu Imperial, POB Cat. B, maço 29, Doc. 1046).

19 Carta da Princesa Francisca a D. Pedro II. Richmond, 7 de janeiro de 1856. (AGP, XXVIII-1).

3020 Diário da Princesa Isabel, 9 de setembro de 1856. (AGP).

21 Parte do documento, Atribuições da aia [1857]. (Museu Imperial, POB-maço 29, Doc. 1038).

22 Parte do documento, Atribuições da aia [1 857] (Museu Imperial, POB-maço 29, Doc. 1038).

23 Carta da Princesa Francisca a D. Pedro II. Claremont, 4 de setembro de 1858. (Apud LACOMBE, 1989). (AGP, XXVIII-1).

24 Maria Amélia Teresa de Bourbon foi rainha dos franceses entre 1830 e 1848. Após a Revolução de 1848 na França, exilou-se com sua família em um sítio na cidade de Claremont, região do sul da Inglaterra. Maria Amélia destacava-se por ter recebido uma educação tão esmerada que era denominada de La Santa por seus familiares. Sobre o assunto ver Encyclopæedia Britannica.

25 Carta da rainha Maria Amélia (França) a D. Pedro II. Claremont, 7 de fevereiro de 1857. O documento original em francês foi traduzido por Thaís Martins, arquivista do Museu Imperial. (AGP, CCXIX-1).

26 Elie Antun Lubbus, também conhecido como Elias Antonio Lopes, comerciante luso-libanês. (DANTAS, 2007).

27 Sobre o assunto ver Aguiar (2012).

28 Segundo Rodrigues e Vasconcelos (2010, p. 5-6), em meados do século XIX, Madame Jenny Diémer também foi diretora de uma conceituada casa de educação feminina estabelecida em Petrópolis na rua central do Quarteirão Francês, atual Rua de Joinville. O proprietário do estabelecimento era Alphonse Diémer, marido de Jenny Diémer, cuja senhora "[...] cuidava de suas alunas com 'esmerado zelo' conforme a propaganda colocada nos periódicos da época." 
29 Carta da Princesa Isabel a D. Teresa Cristina. São Cristóvão, 4 de outubro de 1859. (AGP-XLI-4).

30 Carta da Princesa Isabel a D. Teresa Cristina. São Cristóvão, 11 de outubro de 1859. (AGP-XLL-4).

31 Carta da Princesa Isabel a D. Teresa Cristina. São Cristóvão, 17 de outubro de 1859. (AGP-XLI-4).

32 Com o objetivo de fortalecer a imagem de monarca erudito, D. Pedro II preocupou-se intensamente com a aquisição de livros. Segundo Dantas (2007, p. 134-135), "[...] no período após o banimento da Família Imperial, a coleção bibliográfica contava com aproximadamente 31.670 livros e era composta de obras de literatura de diversos países e de assuntos ligados às ciências naturais e sociais, cuidada pelo bibliotecário Inácio Augusto César Raposo."

33 Carta de D. Pedro II a Princesa Isabel. [Sem local], 14 de março de 1862. (AGP, XXXIX-1).

34 Carta de D. Pedro II à Princesa Isabel. [Sem local], 15 de março de 1862. (AGP, XXXIX-1).

35 Diário do Imperador D. Pedro II. [Sem local], 31 de janeiro de 1861. (Caderneta 9- POB-maço 37. Doc 1057).

36 Carta de D. Pedro II à Princesa Isabel. Recife, 18 de dezembro de 1859. (AGP, XXXIX-1).

37 Carta de D. Pedro II à Princesa Isabel. Rio de Janeiro, 24 de março de 1861. (AGP, XXXIX-1).

38 Carta de D. Pedro II à Princesa Isabel. Rio de Janeiro, 28 de março de 1861. (AGP, XXXIX-1).

39 Cândido José de Araújo Viana - Visconde e Marquês de Sapucai, foi mestre do Imperador e posteriormente, das Princesas. Cf. Livro de Assentamento dos Mestres de Sua Majestade o Imperador e Sereníssimas Senhoras Princezas - 1833-64- Mordomia da Casa Imperial (Arquivo Nacional, Códice 01 - volume 81 l) e cartas escritas por Isabel ao pai especialmente no período de 1857 a 1860. (AGP, XLL-3).

40 João de Barros, autor clássico da Literatura Portuguesa.

41 Diário do Imperador D.Pedro II [Sem local], 5 de janeiro de 1862. (Museu Imperial, Caderneta 9 - POB- maço 37 Doc. 1057).

42 Cf. Papéis relativos à educação das Princesas. (Museu Imperial, 12 páginas de texto, maço 29 - Doc. 1038).

43 Quadro construído com base em Papéis relativos à educação das Princesas (Museu Imperial, maço 29 -Doc. 1038-1862) e transcrito do estudo de AGUIAR (2012, p. 224).

44 CALMON, Pedro. (1941). LACOMBE, Lourenço Luiz. (1989). BARMAN, Roderick (2005). DAIBERT JR, Robert. (2007). VIEIRA, Hermes (1989).

45 Carta da Princesa Leopoldina a D. Pedro II. São Cristóvão, 2 de dezembro de 1858. (AGP- XLVIII- 1 ).

46 Carta da Princesa Isabel a D. Pedro II. São Cristóvão, 2 de dezembro de 1858. (AGP, XLL-3).

47 Carta (Rascunho) de D. Pedro II à Princesa Francisca. Rio de Janeiro, 2 de setembro de 1863. A caligrafia é da Imperatriz D. Teresa Cristina. Na parte superior do papel está escrito: cópia. Rio, 21 de setembro de 1863: "Cara Mana, Cumpre-me tratar do casamento de minhas filhas, e de ti espero o que me afiança nossa amizade de tantos annos. [...] Sabes tão bem como eu o caracter que deve ter sobretudo o marido de lzabel porem que há de ser imperioza, e o contrario a irmaã, e que procurei dar-thes conhecimentos mais proprios do outro sexo. Os maridos devem 
corrigir os caracteres d'ellas, para o que é preciso para que não se respeitem unicamente por dever [...]." (AGP, XXXIX - 8).

\section{Referências}

AGUIAR, Jaqueline Vieira de. Mulheres educadas para governar: o cotidiano das "lições" nas cartas das Princesas Isabel e Leopoldina. 2012. 286 f. Dissertação (Mestrado em Educação) - Programa de Pós-Graduação em Educação, Universidade Católica de Petrópolis, Petrópolis, 2012.

ARGON, Maria de Fátima Moraes. A princesa desconhecida. Revista Nossa História, Rio de Janeiro, v. 3, n. 36, p. 74-77, 2006.

ATRIBUIÇÕES [da] Aia. 1857. Petrópolis, Museu Imperial. (POB-maço 29, Doc. 1038).

BARMAN, Roderick. Princess D. Isabel of Brazil: gender and power in the nineteenth century. Wilmington: Scholarly Resources, 2002.

BARMAN, Roderick. Princesa Isabel do Brasil: gênero e poder no século XIX. São Paulo: UNESP, 2005.

BASTOS, Maria Helena Camara, CUNHA, Maria Teresa Santos, MIGNOT, Ana Chrystina Venancio (Org.). Destinos das letras: história, educação e escrita epistolar. Passo Fundo: UPF, 2002.

BOLETIM [da] Princesa Isabel. 1864. Arquivo Grão Pará. Petrópolis/RJ.

BRAGANÇA, Carlos Tasso de Saxe-Coburgo e. A Princesa dona Leopoldina. Revista do Instituto Histórico e Geográfico Brasileiro, Rio de Janeiro, v. 243, p. 72-93, abr./jun. 1959.

"A princesa flor" - dona Maria Amélia, a filha mais linda de D. Pedro I do Brasil e IV do Nome de Portugal. Madeira: Funchal, 2009.

BRASIL. Decreto Imperial de 15 de outubro de 1827. Disponível em: http://www.planalto. gov.br/ccivil_03/Leis/LIM/LIM-15-10-1827.htm. Acesso em: 5 nov. 2012.

CALMON, Pedro. A Princesa Isabel: a "Redentora". São Paulo: Companhia Editora Nacional, 1941.

CARTA [de] D. Pedro II à Princesa Francisca. (Rascunho). Rio de Janeiro, 2 de setembro de 1863. (Arquivo Grão Pará, XXXIX - 8). 
CARTA [da Princesa Francisca a D. Pedro II. Richmond, 7 de janeiro de 1856. (Arquivo Grão Pará, XXVIII - 1).

CARTA [da] Princesa Isabel a D. Pedro II. São Cristóvão, 11 de abril de 1856 (Arquivo Grão Pará, XLI -3).

CARTA [da] Princesa Isabel a D. Pedro II. São Cristóvão, 2 de dezembro de 1858 (Arquivo Grão Pará, XLI -3).

CARTA [da] Princesa Isabel a D. Teresa Cristina. São Cristóvão, 4 de outubro de 1859. (Arquivo Grão Pará, XLI -4).

CARTA [da] Princesa Isabel a D. Teresa Cristina. São Cristóvão, 11 de outubro de 1859. (Arquivo Grão Pará, XLI -4).

CARTA [da] Princesa Isabel a D. Teresa Cristina. São Cristóvão, 17 de outubro de 1859. (Arquivo Grão Pará, XLI -4).

CARTA [da] Princesa Leopoldina a D. Pedro II. São Cristóvão 2 de dezembro de 1858. (Arquivo Grão Pará, XLVIII -1).

CARTA [de] D. Pedro II à Princesa Isabel. Recife, 28 de novembro de 1859. (Arquivo Grão Pará).

CARTA [de] D. Pedro II à Princesa Isabel. [Sem local]14 de março de 1862 (Arquivo Grão Pará).

CARTA [de] D. Pedro II à Princesa Isabel. [Sem local]1 5 de março de 1862 (Arquivo Grão Pará).

CARTA (rascunho) [de] D. Pedro II a D. Amélia Imperatriz do Brasil. [1853], Petrópolis, Museu Imperial]. (POB Cat. B, maço 29, Doc. 1046).

DAIBERT JR, Robert. Princesa Isabel (1846-1921); a política do coração entre o trono e o altar. 2007. 302f. Tese (Doutorado em História Social) - Programa de Pós-Graduação em História Social, Universidade Federal do Rio de Janeiro, Rio de Janeiro, 2007.

DANTAS, Regina Maria Macedo Costa. A casa do imperador: do Paço de São Cristóvão ao Museu Nacional. 2007. 276f. Dissertação (Mestrado em Memória Social) Programa de Pós-graduação em Memória Social, Universidade Federal do Estado do Rio de Janeiro, Rio de Janeiro, 2007.

DIÁRIO do Imperador [D. Pedro II]. 31 de janeiro de 1861. Petrópolis, Museu Imperial. (Caderneta 9 - POB- maço 37. Doc. 1057). 
FALLAS DO THRONO [desde] o anno de 1823 até o ano de 1889. Acompanhadas dos respectivos votos de graças da Câmara Temporária. Rio de Janeiro: Imprensa Nacional, 1889. (Museu Imperial).

LACOMBE, Lourenço Luiz. Isabel, a Princesa redentora. Petrópolis: Instituto Histórico de Petrópolis, 1989.

LIVRO de assentamento dos mestres [de sua majestade] o Imperador e Sereníssimas Senhoras Princezas. 1833-1864. Mordomia da Casa Imperial - (Arquivo Nacional - Códice 01 volume 811 .

PAPÉIS relativos à educação [das] princesas. [1857-1863]. Petrópolis: Museu Imperial. (Maço 29 - Doc. 1038).

QUEIRÓS, Diná Silveira de. A Princesa dos escravos: Isabel para a juventude. Rio de Janeiro: Record, 1966.

RODRIGUES, Maria das Graças Duvanel; VASCONCELOS, Maria Celi Chaves. Mulheres educadas e mulheres educadoras no Brasil oitocentista: perspectivas biográficas de Madame Diémer. CONGRESSO INTERNACIONAL DE PESQUISA (AUTOI BIOGRÁFICA, 4; 2010, São Paulo. Anais... São Paulo: Universidade de São Paulo, 2010.

34 VASCONCELOS, Maria Celi Chaves. A casa e seus mestres: a educação no Brasil de oitocentos. Rio de Janeiro: Gryphus, 2005.

VIEIRA, Hermes. A Princesa Isabel, uma vida de luzes e sombras. São Paulo: GRD, 1989.

Profa. Ms. Jaqueline Vieira de Aguiar Fundação de Apoio à Escola Técnica do Estado do Rio de Janeiro IFAETEC Escola Estadual Visconde Mauá | EEEFVM Departamento de História Secretaria de Estado de Educação | SEEDUC Grupo de Pesquisa "História e Memória das Políticas Educacionais no Território Fluminense" | CNPq Email | profajaqueaguiar@gmail.com 
Profa. Dra. Maria Celi Chaves Vasconcelos Programa de Pós-Graduação em Educação da Universidade Católica de Petrópolis Universidade do Estado do Rio de Janeiro

Faculdade de Educação Coordena o Grupo de Pesquisa "História e Memória das Políticas Educacionais no Território Fluminense" | CNPq Pesquisadora do CNPq Jovem Cientista | FAPERJ Email | maria.celi@ucp.br

Recebido 02 dez. 2012 Aceito 15 jan. 2013 